employees and between service departments. Cooperation may ultimately lead the ideal of team work to merge in that of ' group work', groups having only their own ignorance or inefficiency as enemy, and in organisation by technical processes rather than by sciences.

THE matter of publication is not without concern to the relations of science and industry, as pointed out by Dr. Peirce, and a generous policy of publication for lines of pure scientific interest has a stimulating effect on the research staff from which the industry itself is the first to benefit. Publication assists in securing the recognition and interest from the universities, which are essential for open discussion, for combating the natural secretiveness of industry, and for creating a technical literature in which systematic cross reference becomes possible. These and other problems relating to the scientific reputation of the individual, the place of individual initiative and originality in co-operative research, are aspects of the relations between science and industry which are a modern phase of the conflict between authority and liberty. Much also remains to be done in redressing the present neglect of the borderland sciences, and cotton itself is of special interest in the borderland of physics. Finally, Dr. Peirce suggests that by overcoming the technical difficulties of industry the scientific worker may remove obstacles to the development of beauty, and thus contribute to the artistic as well as to the humane aspect of industry.

\section{Social Discontent and its Remedy}

IT is not altogether a new explanation of the social ills of the day to find a psychological rather than an economic explanation, but the theme is one that may well be stressed, and is ably expounded by Mr. H. A. Bruce in a paper on "The Sources of American Discontent" (Proc. Amer. Acad. Arts and Sci., vol. 67, No. 3, Feb. 1932). The social evils and discontent which $\mathrm{Mr}$. Bruce cites as being prevalent in America to-day are no less evident in many parts of Europe, and he finds the chief cause to lie in modern industrialisation, which not only narrows and starves the needs of the individual life, but also results in that crowding which leads to crowd mentality and all its drawbacks. The present state of affairs leads to discontent, adds to the prison population, the numbers of mental and nervous wrecks, and takes a mounting toll of suicides and lives shortened by bodily diseases promoted by mental stress. Mr. Bruce admits the seriousness of the problem and the difficulties of solution when national policies are determined by majorities infused with the crowd spirit and on an arrested level of mental activity, but he makes the suggestion that the crowd spirit may itself be used to contribute to the acceptance of a wiser philosophy of life than is summed up in making money, spending money, and amusing oneself. Intensive education of a far-spreading kind is the agency to apply in changing the outlook of industrialised peoples, and leading them to an appreciation of values other than those which prevail to-day.

No. 3266, VoL. 129]

\section{Hydrogen and its Uses}

Dr. E. F. Armstrong recently delivered a lecture on hydrogen and its uses before the Royal Society of Arts (J. Roy. Soc. Arts, May 6). Two important methods of preparation of hydrogen are from water gas and coke oven gas. The carbon monoxide in water gas is oxidised to carbon dioxide by passing a mixture of the gas and steam over a catalyst containing iron oxide, the hydrogen of the reacting steam being set free. The small residue of carbon monoxide is removed by absorption under 200 atm. pressure. The preparation from coke oven gas depends on purification by washing and fractional cooling, whereby first the methane and then the carbon monoxide is removed. The cost of production by either method under the most favourable conditions is about $1 s$. per thousand cubic feet of hydrogen. The principal uses of hydrogen are for the hydrogenation of fats, in which liquid oils are converted into solid fats by taking up hydrogen in the presence of small quantities of nickel; the hydrogenation of other organic materials, including mineral oil, tar, and coal; and the production of synthetic ammonia. The conversion of coal into oil by treatment with hydrogen under pressure involves the use of an elaborate and costly plant; and so far as the production of petrol is concerned, the cost is put down at $7 d$. $-8 d$. per gallon, as compared with a price of less than $2 d$. per gallon at the oilfield. The prices may alter in future in favour of petrol from coal. If hydrogen is ever required in larger quantities by the oil industry, it could be obtained from the methane of natural gas or refinery waste gas, which readily reacts with steam to form hydrogen and carbon dioxide.

\section{The National Physical Laboratory}

The Report of the National Physical Laboratory for the year 1931 is an illustrated quarto volume of 131 pages (London: H.M. Stationery Office, $15 s$. net). As usual, it gives a readable and interesting account of the progress of the work of each department without introducing technical details, and equally as usual, that progress must be gratifying to the Board and to the staff. The new physics building is now in use and the old quarters of physics are occupied by electrical standards. The compressed air tunnel building is completed, the new tank will be completed this year, and the new acoustics building has been commenced. Dr. W. Rosenhain has left to take up other work, Prof. C. H. Desch of Sheffield succeeds him, while Dr. W. E. Dye has been lost by death. Ninety-seven official papers by members of the staff have been published during the year in the scientific or technical journals or in the proceedings of societies. We note the determination of the yard and metre in terms of the wave-length of the red cadmium line, the accurate measurement of time for radio frequencies, and an international agreement as to colour standardisation. Routine tests of almost all types have with few exceptions, decreased. In the watch tests, the success of one Swiss firm is very remarkable. 